TITLE:

\title{
Triple Helix Formation in a Topologically Controlled DNA Nanosystem
}

\section{AUTHOR(S):}

Yamagata, Yutaro; Emura, Tomoko; Hidaka, Kumi; Sugiyama, Hiroshi; Endo, Masayuki

\section{CITATION:}

Yamagata, Yutaro ...[et al]. Triple Helix Formation in a Topologically Controlled DNA Nanosystem. Chemistry - A European Journal 2016, 22(16): 5494-5498

\section{ISSUE DATE:}

2016-04-11

URL:

http://hdl.handle.net/2433/230930

\section{RIGHT:}

(c) 2016 WILEY-VCH Verlag GmbH \& Co. KGaA, Weinheim. This is the peer reviewed version of the following article: Yutaro Yamagata, Tomoko Emura, Kumi Hidaka, Hiroshi Sugiyama and Masayuki Endo, "Triple Helix Formation in a

Topologically Controlled DNA Nanosystem, " Chemistry A European Journal, 2016, 22(16), 5494 -5498, which has been published in final form at https://doi.org/10.1002/chem.201505030. This article may be used for non-commercial purposes in accordance with Wiley Terms and Conditions for Self-Archiving. The full-text file will be made open to the public on 11 April 2017 in accordance with publisher's 'Terms and Conditions for Self-Archiving'. This is not the published version. Please cite only the published version. この論文は出版社版でありません。引用の際には出版社版を ご確認ご利用ください。 


\title{
Triple Helix Formation in a Topologically Controlled DNA
} Nanosystem

\author{
Yutaro Yamagata ${ }^{[b]}$ Tomoko Emura, ${ }^{[b]}$ Kumi Hidaka, ${ }^{[b]}$ Hiroshi Sugiyama, ${ }^{*[a]}[b]$ Masayuki Endo ${ }^{\star[a]}$
}

Abstract: In the present study, we demonstrate single-molecule imaging of triple helix formation in DNA nanostructures. The binding of the single-molecule third strand to double-stranded DNA in a DNA origami frame was examined using two different types of triplet base pairs. The target DNA strand and the third strand were incorporated into the DNA frame, and the binding of the third strand was controlled by the formation of Watson-Crick base pairing. Triple helix formation was monitored by observing the structural changes in the incorporated DNA strands. It was also examined using a photocaged third strand wherein the binding of the third strand was directly observed using high-speed atomic force microscopy during photoirradiation. We found that the binding of the third strand could be controlled by regulating duplex formation and the uncaging of the photocaged strands in the designed nanospace.

Triple helices are fundamental variants of DNA structure and have several biological applications, including the sequenceselective recognition of double helices. [1] [2] A triple helix is formed by the recognition of the poly-purine $(\mathrm{Pu})$ /poly-pyrimidine (Py) double-stranded DNA (dsDNA) by a poly-Py third strand. ${ }^{[3]}$ [4] [5] [6] The poly-Py third strand binds to the poly-Pu strand in Watson-Crick (WC) base pairs in parallel orientation via Hoogsteen base pairing. Selective binding of the external strand to a particular domain of the dsDNA allows for the delivery of DNA-cleaving agents to the target site in large dsDNA structures, including chromosomes. ${ }^{[7]}{ }^{[8]}$ Variations in the triple helix have been explored to expand the recognition sequences. A poly- $\mathrm{Pu}$ third strand that identifies $\mathrm{Pu}$ in WC base pairs in antiparallel orientation has been shown to recognize the four WC base pairs [9] [5] Moreover, non-canonical bases have been incorporated into the third strand to recognize the four WC base pairs. [10] Recently, triplex formation has found application in $\mathrm{pH}$ responsive DNA devices and hydrogels. ${ }^{[11]}[12][13]$

The recent emergence of DNA origami technology allows for the design and construction of various DNA nanostructures. ${ }^{[14]}$ It offers a versatile scaffold for the placement of substrate DNA strands to observe single biomolecules at molecular resolution. The DNA strands can be selectively incorporated into the four connection sites in the DNA origami frame, so that the distances between the incorporated DNA strands can be controlled and their orientations aligned. [15] Triple helix formation has been utilized to modify DNA nanostructures with functional groups attached to the third strand. ${ }^{[16]}[17]$

[a] Prof. Dr. M. Endo, Prof. Dr. H. Sugiyama Institute for Integrated Cell-Material Sciences (WPI-iCeMS) Kyoto University

Yoshida-ushinomiyacho, Sakyo-ku, Kyoto 606-8501, Japan endo@kuchem.kyoto-u.ac.jp; hs@kuchem.kyoto-u.ac.jp

[b] Y. Yamagata, T. Emura, K. Hidaka, Prof. Dr. Sugiyama Department of Chemistry, Graduate School of Science Kyoto University

Kitashirakawa-oiwakecho, Sakyo-ku, Kyoto 606-8502, Japan

Supporting information for this article is given via a link at the end of the document (a)
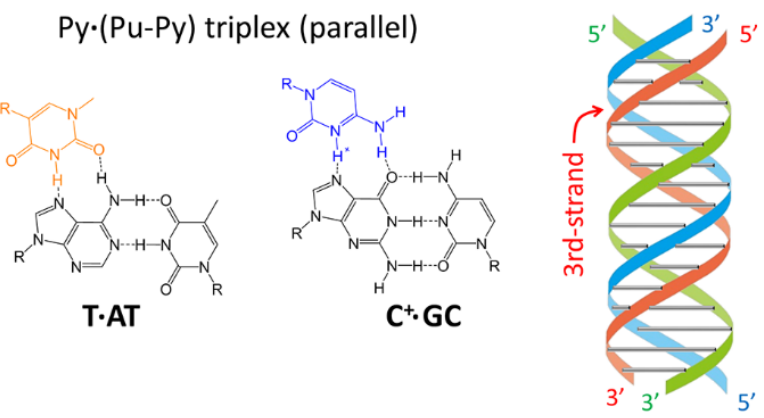

(b)
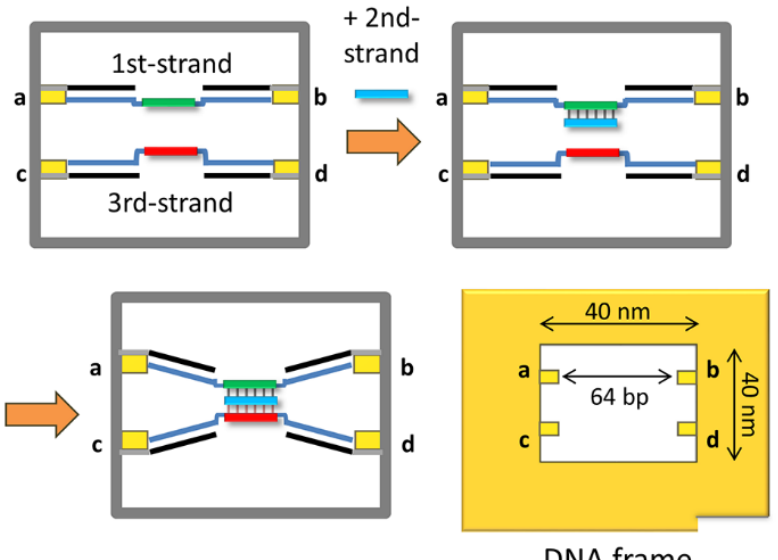

(c)

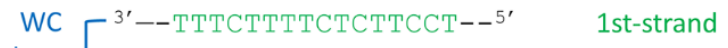

$$
\begin{aligned}
& \text { base } L \text { 5' AAAGAAAAGAGAAGGA 3' 2nd-strand }
\end{aligned}
$$

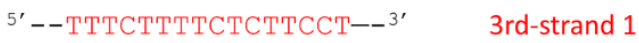

$$
\begin{aligned}
& \text { 5'-TTTG-TTTCTTTTCTCTTCCT-GTTT-3' 3rd-strand } 2
\end{aligned}
$$

Figure 1. Single-molecule observation of triple helix formation in a DNA frame (a) Left: Py-(Pu-Py) triplet base pairings; T.AT and $\mathrm{C}^{+} \cdot \mathrm{GC}$ triplet, in which the $\mathrm{C}$ in the third strand needs protonation at the N3 position for Hoogsteen base pairing. Right: triple helix in antiparallel orientation. (b) Schematic representation of DNA strands incorporated into the DNA frame. The poly-Py first strand of the WC base pair was incorporated into the upper side of the DNA frame and the poly-Py third strand into the lower side. (c) DNA sequences used in the experiment. Two different lengths of third strands were used.

High-speed atomic force microscopy (AFM) measurements have been used recently to probe DNA nanostructures and their reactivity at the single-molecule level. [15] [18] In these experiments, the individual DNA nanostructures were assembled in the DNA origami frame, and the reactions of the nanostructures were elucidated by analyzing the DNA frames. This method can be used for the single-molecule visualization of enzymatic processes in the DNA nanostructures. [19] [20] [21] [22] Gmultiplex and i-motif structures, and their reconfiguration, ${ }^{[23]}[24]$ [25] [26] B-Z transitions, [27] and the imaging of the DNAzyme reaction [28] in the DNA nanostructures has also been demonstrated. 
(a) 1 st +3 rd-strand 1

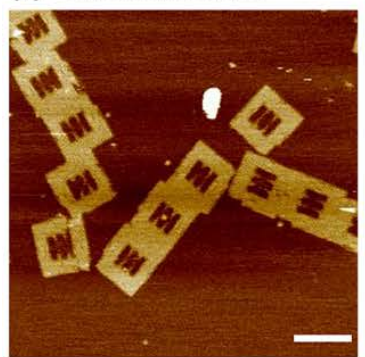

(b) 1 st +3 rd-strand 2
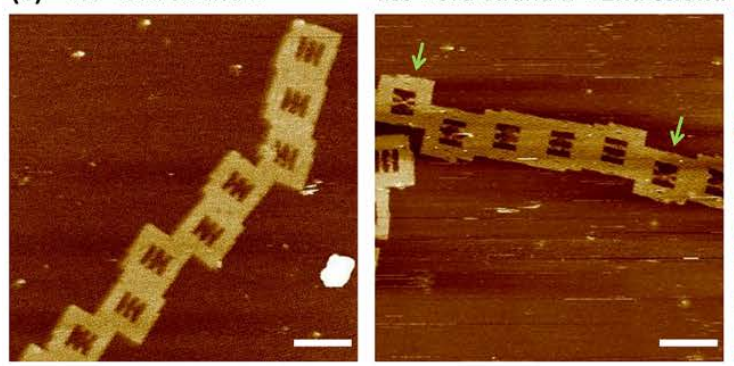

1 st +3 rd-strand $1+2$ nd-strand
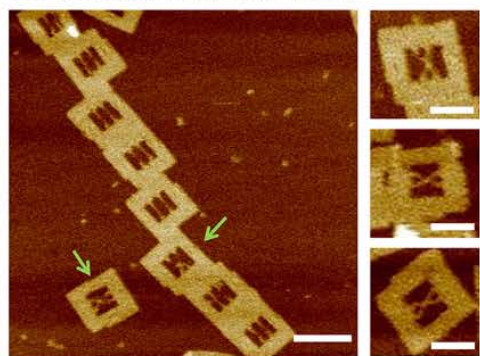

$1 s t+3 r d-s t r a n d ~ 2+2 n d-s t r a n d$

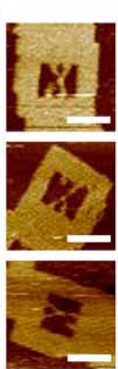

(c)

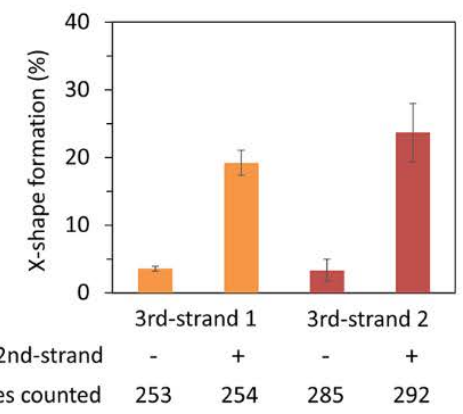

(d)
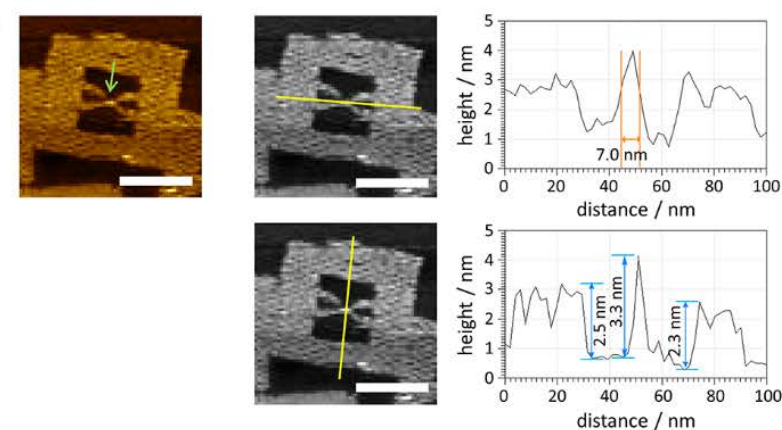

Figure 2. Single-molecule observation of Py-(Pu-Py) triple helix formation in a DNA frame. (a) Left: AFM image of the incorporated first strand and third strand 1 in the DNA frame. Right: AFM image after incubation of the first strand and third strand 1 with the second strand. Arrows indicate connected strands (X-shape formation). Scale bar $100 \mathrm{~nm}$. Individual images of connected strands in the DNA frame. Scale bar $50 \mathrm{~nm}$. (b) Left: AFM image of the incorporated first strand and third strand 2 in the DNA frame. Right: AFM image after incubation of the first strand and third strand 2 with the second strand. Scale bar $100 \mathrm{~nm}$. Individual images of connected strands in the DNA frame. Scale bar $50 \mathrm{~nm}$. (c) Summary of the observed connection (X-shape formation) in the absence and presence of the second strand. The data were obtained from three independent experiments. Error bars represent the standard deviations (SD). (d) Section analysis of the connected domain (arrow) of the first/second/third strand 2 triplex. Section profiles of length (top) and height (bottom) of connected domain. Scale bar $50 \mathrm{~nm}$.
In the present study, we applied high-speed AFM to follow triple helix formation at the single-molecule level. First, we examined the triplet Py-(Pu-Py) for triplex formation (Figure 1a) To observe the binding of the third strand to dsDNA, we introduced the poly-Py strand of the dsDNA into the upper side of the DNA frame, and the poly-Py third strand into the lower side. We controlled the third strand binding by the addition of the poly-Pu strand of the dsDNA (second strand) to the top strand in the DNA frame (Figure 1b). ${ }^{[19]}$ Without the second strand, the third strand cannot form the triple helix, and it results in the first and the third strands remaining separate. Only the target sequences are exposed and the other sites are covered by the dsDNA. Figure 1c shows the DNA sequences we used in this study. We used two different lengths of the third strand, one of which had four nucleotide spacers at both the sides to facilitate triple helix formation.

We examined the formation of the triple helix in solution using the above-mentioned strands. We measured the melting temperature $\left(T_{\mathrm{m}}\right)$ using the same buffer that was used for the DNA nanostructure formation. The buffer contained $20 \mathrm{mM}$ Tris$\mathrm{HCl}$ buffer ( $\mathrm{pH}$ 7.0), $10 \mathrm{mM} \mathrm{MgCl}_{2}$, and $1 \mathrm{mM}$ EDTA (Figure S1). We observed the dissociation of the triplex and duplex structures in the melting profiles. The melting curve for the antiparallel triplex was clearly observed. In the case of the parallel triplex, dissociation was not observed clearly. It might be due to the low hyperchromicity of the third strand dissociation. ${ }^{[29]}$ In both the types of triplexes, the melting temperatures were found to be above $30^{\circ} \mathrm{C}$. We used the solution condition of the helices for the AFM observations.

We next prepared the DNA nanostructure samples. DNA frames were prepared in the solution as described in a previous study. ${ }^{[19]}$ We connected the first and third strands to the upper and lower sides of the DNA frame respectively, using the four single-stranded DNA tethers as linkers (Figures $1 \mathrm{~b}$ and S2). First, we examined the two strands in the DNA frame without the addition of the second strand. Without the second strand, the two incorporated strands were separate in most samples; connected strands were observed in about $3 \%$ of the frames for both lengths of the third strand (Figures 2, S4, and S5). Next, we added the second strand to the DNA frame having the two preincorporated strands. We used AFM to observe the structures after incubation with the second strand and found an increase in the connected (X-shaped) strands in the DNA frame. In the case of the third strand without the spacers (third strand 1), the proportion of the connected structures increased to $19 \%$, suggesting that the addition of the second strand induced triple helix formation in the DNA frame. Using the third strand with spacers (third strand 2), the proportion of connected structures increased to $24 \%$. In the formation of the triple helix in the DNA frame, third strand binding resulted in structural stress caused by the topological connection of the top and bottom strands. By reducing this structural stress, the spacers worked to increase the yield of the triplex formation.

We further analyzed the connected domain in the X-shaped structure. We obtained the section profiles of length and height 
(a) (Py-Pu) $\cdot$ Pu triplex (antiparallel)



TA.A

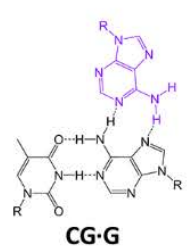

CG.G (b)

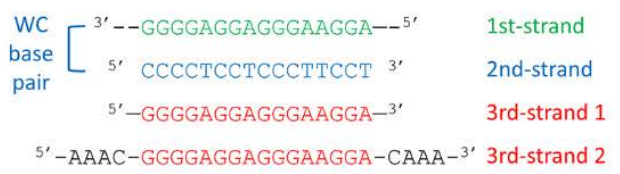

(c) 1 st +3 rd-strand 1

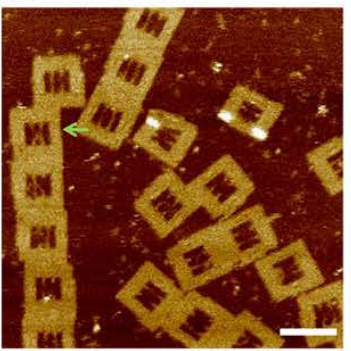

(d) 1 st +3 rd-strand 2

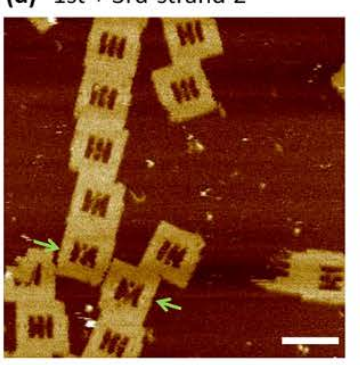

$1 s t+3$ rd-strand $2+2$ nd-strand


(e)

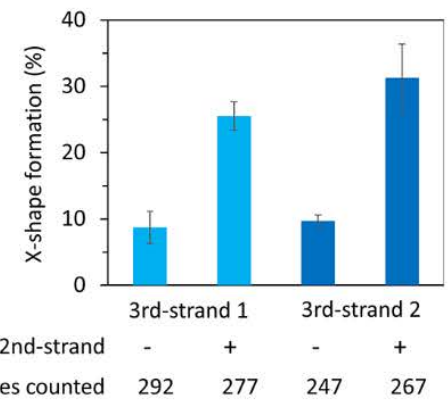

$\begin{array}{lllll}\text { DNA frames counted } & 292 & 277 & 247 & 267\end{array}$

of the connected domain containing the first/second/third strand 2 from the AFM image (Figure 2d). The length of the connected domain was found to be $7.0 \mathrm{~nm}$, which corresponds to the length of 20 base pairs. We used the 16 bp triplex with the fournucleotide spacers at both the sides, so that the triplex would fully form in the connected domain. In addition, the height of the connected domain $(3.3 \mathrm{~nm})$ was larger than that of the bundled duplexes in the DNA frame $(2.3-2.5 \mathrm{~nm})$. This also shows that the connected domain contains the triple helices. In the individual DNA frames presented in Figure $2 a$ and $2 b$, we observed a higher part in the center of the $\mathrm{X}$-shaped structure measuring about 5-10 $\mathrm{nm}$ in length. This also indicates the formation of the triple helix and its detection in this system.
The Py-(Pu-Py) triple-helix formation is $\mathrm{pH}$ sensitive. The protonation of the cytosine base promotes the binding of the third strand and makes the triplex more stable in acidic conditions (Figure S8). We examined triplex formation with third strand 2 at $\mathrm{pH} 6.5$ and 6.0. Using the same method for triplex formation in the DNA frame as described above, we observed the connection (X-shaped structure) in $46 \%$ and $51 \%$ of the frames at pH 6.5 and 6.0, respectively (Figures S9, 10). Without the second strand, $11 \%$ and $20 \%$ of frames formed the $X$ shaped structure at $\mathrm{pH} 6.5$ and 6.0, respectively. Hence, although a lower $\mathrm{pH}$ promoted triplex formation, the nonspecific binding without the second strand was also observed more frequently in the nanospace.

We also examined the other type of triplet base pairing (Py$\mathrm{Pu}$ )-Pu (Figure $3 \mathrm{a}$ ). In this case, the poly-Pu third strand binds to the poly-Pu strand in the poly-Py/poly-Pu dsDNA in an antiparallel orientation (Figures $3 \mathrm{~b}$ and S3). ${ }^{[9]}$ We incorporated the first strand and the third strand into the upper and lower sides in the DNA frame, respectively. When the two strands were incorporated, the proportion of connected strands using the third strand 1 and 2 were $8.7 \%$ and $9.7 \%$, respectively (Figures 3c, 3d, S6, and S7). In the (Py-Pu)-Pu triplet, the poly-Pu third strand binds to the poly-Pu first strand in parallel orientation. In solution, it would be difficult to form a poly-Pu/poly-Pu duplex in parallel orientation because of the conformation of the backbone. In the nanospace, the orientation of two strands was aligned in the DNA frame and the two poly-Pu strands were brought close enough to interact. After incubation with the second strand, the connected strands were observed using the third strand 1 and 2 in $26 \%$ and $31 \%$ of the frames, respectively. As with the earlier experiment, the spacers of the third strand helped in the formation of the triplex.

Figure 3. Single-molecule observation of (Py-Pu)-Pu triple helix formation in the DNA frame. (a) (Py-Pu)-Pu triplet base pairings; TA.A and CG.G triplet and triple helix in parallel orientation. (b) DNA sequences used in the experiment. Two different lengths of the third strand were used. (c) Left: AFM image of the incorporated first strand and third strand 1 in the DNA frame. Right: AFM image after incubation of the first strand and third strand 1 with the second strand. Scale bar $100 \mathrm{~nm}$. Arrows indicate connected strands (Xshape formation). Individual images of connected strands in the DNA frame. Scale bar $50 \mathrm{~nm}$. (d) Left: AFM image of the incorporated first strand and third strand 2 in the DNA frame. Right: AFM image after incubation of the first strand and third strand 2 with the second strand. Scale bar $100 \mathrm{~nm}$. Individual images of connected strands in the DNA frame. Scale bar $50 \mathrm{~nm}$. (e) Summary of the observed connection (X-shape formation) in the absence and presence of the second strand. The data were obtained from three independent experiments. Error bars represent the SD.

To observe the change in the configuration of the target duplex and the third strand during triple helix formation, we introduced a photocaged group in the third strand. We prepared a sample using the Py-(Pu-Py) triplex with the first strand and the third strand containing photocaged thymidines (Ts) (Figure $4 a)$. The first strand and the caged third strand were connected to the upper and lower sides in the DNA frame, respectively. The second strand was then introduced to the frames and incubated. Photocaged T has a 6-nitropiperonyloxymethyl (NPOM) group at the N3 position ${ }^{[30]}$ that prevents the binding of the third strand. 
We incorporated two caged Ts into the third strand. After assembling the strands, the strand configurations were observed in the DNA frame. Just after the assembly, the proportion of $X$ shaped formations was $6.7 \%$ (Figures $4 \mathrm{~b}$ and $\mathrm{S} 8$ ). This sample was then treated with UV irradiation at $25^{\circ} \mathrm{C}$ for $10 \mathrm{~min}$ to remove the caged group. Under this condition, the photocaged groups were removed from the DNA strand (Figure S11). Following the irradiation, the photocaged group was removed completely. After photoirradiation, the proportion of connected strands (X-shaped structures) increased to 33\% (Figures $4 \mathrm{~b}$ and $\mathrm{S} 12)$. These results indicate that triple helix formation was controlled in the nanospace by the photoreaction.

(a) Py·(Pu-Py) triplex (parallel)


(b) No UV irradiation

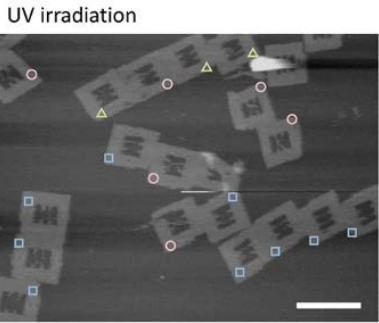

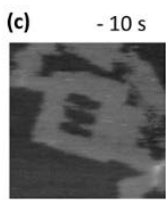

$15 \mathrm{~s}$



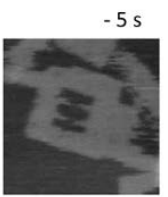

$20 \mathrm{~s}$

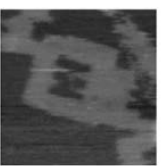

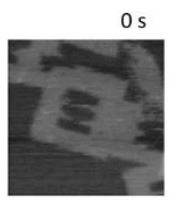

$25 \mathrm{~s}$

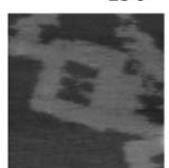

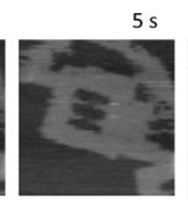

$30 \mathrm{~s}$





$35 \mathrm{~s}$

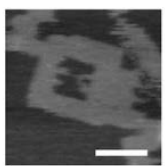

Figure 4. Single-molecule observation of triple helix formation in a DNA frame using the photocaged third strand. (a) DNAzyme and the substrate sequence used in the experiments. Removal of the photocaged group induced the binding of the third strand to the specific sequence of dsDNA. Structure of N36-nitropiperonyloxymethyl (NPOM) thymidine. (b) AFM image of triple helix formation before (left) and after (right) photoirradiation. Triple helix formation can be distinguished by the connection of the two strands in the DNA frame. Separated, connected, and unidentified strands are represented by blue squares, red circles, and green triangles, respectively. Scale bar $50 \mathrm{~nm}$. (c) AFM images at various time points showing the binding of the third strand to the duplex in the DNA frame during photoirradiation. Photoirradiation started at time $0 \mathrm{~s}$. Scanning rate: 0.2 frame/sec. Scale bar $50 \mathrm{~nm}$.

Finally, we used high-speed AFM to image the triplex formation at the single-molecule level. The duplex and the caged third strand were assembled in the DNA frame. During the AFM scanning, irradiation with UV-light was performed. After $10 \mathrm{~s}$ of irradiation, the connection of the two strands in the DNA frame was observed (Figures $4 \mathrm{c}$ and S13, Movie S1). The uncaging of the protecting groups is required for the binding of the third strand to the target dsDNA to form the triple helix. Hence, we could directly observe the binding of the third strand using photochemical reaction and high-speed AFM. This method, therefore, temporally initiated the triple helix formation in the nanospace.

We have demonstrated the formation of a triple helix in the DNA nanostructure. The third strand binding to the dsDNA could be clearly monitored by observing the binding of the two strands incorporated into the DNA frame. Different types of triplet base pairing, $\mathrm{Py}-(\mathrm{Pu}-\mathrm{Py})$ and $(\mathrm{Py}-\mathrm{Pu})-\mathrm{Pu}$, were incorporated, and the strands were arranged in different orientations in the DNA frame. The photoinduced binding of the third strand was controlled by photoirradiation and could be directly visualized by high-speed AFM performed during the same time. This observation system is a practical approach for investigating the interaction of various arrangements of DNA strands in differing orientations, and for monitoring the structural changes induced by the chemical reactions.

\section{Experimental Section}

Materials. All the staple DNAs for the DNA frame were purchased from Eurofins Genomics (Tokyo, Japan). Single stranded M13mp18 viral DNA was purchased from New England Biolabs (Ipswich, MA). The DNA strand containing NPOM-dT was purchased from Japan Bio Services (Saitama, Japan)

Melting temperature measurements. For the formation of the duplex and triplex, DNA strands $(5 \mu \mathrm{M})$ were added to a solution containing 20 $\mathrm{mM}$ Tris- $\mathrm{HCl}$ buffer ( $\mathrm{pH} 7.0), 10 \mathrm{mM} \mathrm{MgCl} 2$, and $1 \mathrm{mM}$ EDTA. The samples were annealed; the Tm profiles were recorded on a JASCO 670 UV/Vis spectrophotometer. The temperature was increased at a rate of $1.0^{\circ} \mathrm{C} / \mathrm{min}$ from $5^{\circ} \mathrm{C}$ to $90^{\circ} \mathrm{C}$.

Preparation of the DNA frame. The DNA frame was assembled in a 25 $\mu \mathrm{L}$ solution containing $8 \mathrm{nM}$ M13mp18 single-stranded DNA, $50 \mathrm{nM}$ staple strands (6.25 eq), $20 \mathrm{mM}$ Tris buffer ( $\mathrm{pH} 7.0), 10 \mathrm{mM} \mathrm{MgCl}_{2}$, and 1 mM EDTA as per a previous study. ${ }^{[20]}$ The mixture was annealed from $85^{\circ} \mathrm{C}$ to $15^{\circ} \mathrm{C}$ at a rate of $-1.0^{\circ} \mathrm{C} / \mathrm{min}$.

Introduction of dsDNAs into the DNA frame. The pre-assembled dsDNAs containing the first and third strand [40 $\mathrm{nM}(5$ eq)] were incorporated into the DNA frame $(8 \mathrm{nM})$ by heating at $40^{\circ} \mathrm{C}$ for $10 \mathrm{~min}$ and then cooling to $15^{\circ} \mathrm{C}$ at a rate of $-1.0^{\circ} \mathrm{C} / \mathrm{min}$ using a thermal cycler. The sample was purified using gel filtration (Sephacryl-300, GE Healthcare). The assembled structures were observed by AFM. Then, the second strand [100 $\mathrm{nM}(12.5 \mathrm{eq})]$ was added to the sample and incubated at $25^{\circ} \mathrm{C}$ for $1 \mathrm{~h}$. The assembled structures were observed by AFM.

AFM imaging of the target dsDNAs in the DNA frame. AFM images were obtained on a Dimension FastScan (Bruker AXS, Madison, WI). The sample $(2 \mu \mathrm{L})$ was absorbed on a freshly cleaved mica plate for 5 min at room temperature, and then washed with the buffer solution for the observation. Scanning was performed in the same buffer solution using a tapping mode.

Incorporation of photocaged strands into the DNA frame and photoirradiation. The preassembled dsDNAs containing the first strand and the photocaged third strand $[40 \mathrm{nM}(5 \mathrm{eq})]$ were incorporated into the DNA frame $(10 \mathrm{nM})$ by heating at $40^{\circ} \mathrm{C}$ for $10 \mathrm{~min}$ and then cooling to $15^{\circ} \mathrm{C}$ at a rate of $-1.0^{\circ} \mathrm{C} / \mathrm{min}$ using a thermal cycler. The sample was 
purified using gel filtration (Sephacryl-300, GE Healthcare). Then, the second strand [100 $\mathrm{nM}(12.5 \mathrm{eq})]$ was added to the sample. Photoirradiation for the sample was performed using Xe-lamp (300 W, Ashahi-spectra MAX-303) with band path filter (350 nm; 10 nm FWHM) at $25^{\circ} \mathrm{C}$ for $10 \mathrm{~min}$. The temperature during the photoirradiation was controlled by using a temperature-controlled dry bath. The samples were observed by AFM before and after photoirradiation.

High-speed AFM imaging. High-speed AFM images were obtained using an atomic-force microscope (Nano Live Vision, RIBM, Tsukuba, Japan) with a silicon nitride cantilever (Olympus BL-AC10EGS). The sample $(2 \mu \mathrm{L})$ was absorbed on a freshly cleaved mica plate for 5 min at room temperature, and then washed with the buffer for observing the photocaged third strand binding. Scanning was performed in the same buffer using the tapping mode. Photoirradiation was carried out directly on the stage of the atomic force microscope (Olympus IX70 microscope) using an Hg-lamp light source (Olympus U-RFL-T) with band path filters (330-380 nm for UV-irradiation).

\section{Acknowledgements}

This work was supported by a Grant-in-Aid for Scientific Research on Innovative Areas "Molecular Robotics" (Grant Number 24104002) of MEXT and JSPS KAKENHI (Grant Numbers 15H03837, 26620133). Financial support from the Kurata Memorial Hitachi Science and Technology Foundation to ME is also acknowledged.

Keywords: DNA origami $\bullet$ triple helix $\bullet$ single-molecule observation $\bullet$ photo reaction $\bullet$ high-speed AFM

[1] A. Jain, G. Wang and K. M. Vasquez, Biochimie 2008, 90, 1117-1130.

[2] M. Duca, P. Vekhoff, K. Oussedik, L. Halby and P. B. Arimondo, Nucleic Acids Res. 2008, 36, 5123-5138.

[3] H. E. Moser and P. B. Dervan, Science 1987, 238, 645-650.

[4] J. S. Sun and C. Helene, Curr. Opin. Struc. Biol. 1993, 3, 345-356.

[5] S. O. Doronina and J. P. Behr, Chem. Soc. Rev. 1997, 26, 63-71.

[6] L. A. Yatsunyk, O. Mendoza and J. L. Mergny, Acc. Chem. Res. 2014, 47, 1836-1844.

[7] S. A. Strobel and P. B. Dervan, Science 1990, 249, 73-75.

[8] S. A. Strobel, L. A. Doucettestamm, L. Riba, D. E. Housman and P. B. Dervan, Science 1991, 254, 1639-1642.

[9] P. A. Beal and P. B. Dervan, J. Am. Chem. Soc. 1992, 114, 4976-4982.

[10] K. R. Fox and T. Brown, Q. Rev. Biophys. 2005, 38, 311-320.
[11] A. Idili, A. Vallee-Belisle and F. Ricci, J. Am. Chem. Soc. 2014, 136, 5836-5839.

[12] A. Porchetta, A. Idili, A. Vallee-Belisle and F. Ricci, Nano Lett. 2015, 15, 4467-4471.

[13] J. T. Ren, Y. W. Hu, C. H. Lu, W. W. Guo, M. A. Aleman-Garcia, F. Ricci and I. Willner, Chem. Sci. 2015, 6, 4190-4195.

[14] P. W. Rothemund, Nature 2006, 440, 297-302.

[15] M. Endo and H. Sugiyama, Acc. Chem. Res. 2014.

[16] D. A. Rusling, I. S. Nandhakumar, T. Brown and K. R. Fox, ACS Nano 2012, 6, 3604-3613.

[17] D. A. Rusling, A. R. Chandrasekaran, Y. P. Ohayon, T. Brown, K. R. Fox, R. Sha, C. Mao and N. C. Seeman, Angew. Chem. Int. Ed. 2014, 53, 3979-3982.

[18] A. Rajendran, M. Endo and H. Sugiyama, Chem. Rev. 2014, 114, 1493-1520.

[19] M. Endo, Y. Katsuda, K. Hidaka and H. Sugiyama, J. Am. Chem. Soc. 2010, 132, 1592-1597.

[20] M. Endo, Y. Katsuda, K. Hidaka and H. Sugiyama, Angew. Chem. Int. Ed. 2010, 49, 9412-9416.

[21] M. Endo, M. Inoue, Y. Suzuki, C. Masui, H. Morinaga, K. Hidaka and H. Sugiyama, Chem. Eur. J. 2013, 19, 16887-16890.

[22] Y. Suzuki, M. Endo, Y. Katsuda, K. Ou, K. Hidaka and H. Sugiyama, J. Am. Chem. Soc. 2014, 136, 211-218.

[23] Y. Sannohe, M. Endo, Y. Katsuda, K. Hidaka and H. Sugiyama, J. Am. Chem. Soc. 2010, 132, 16311-16313.

[24] A. Rajendran, M. Endo, K. Hidaka, P. L. Tran, J. L. Mergny and H. Sugiyama, Nucleic Acids Res. 2013, 41, 8738-8747.

[25] A. Rajendran, M. Endo, K. Hidaka and H. Sugiyama, Angew. Chem. Int. Ed. 2014, 53, 4107-4112.

[26] M. Endo, X. Xing, X. Zhou, T. Emura, K. Hidaka, B. Tuesuwan and H. Sugiyama, ACS Nano 2015, 9, 9922-9929.

[27] A. Rajendran, M. Endo, K. Hidaka and H. Sugiyama, J. Am. Chem. Soc. 2013, 135, 1117-1123.

[28] M. Endo, Y. Takeuchi, Y. Suzuki, T. Emura, K. Hidaka, F. Wang, I. Willner and H. Sugiyama, Angew. Chem. Int. Ed. 2015, 54, 10550-10554.

[29] C. Gondeau, J. C. Maurizot and M. Durand, Nucleic Acids Res. 1998, 26, 4996-5003.

[30] H. Lusic, D. D. Young, M. O. Lively and A. Deiters, Org. Lett. 2007, 9, 1903-1906.

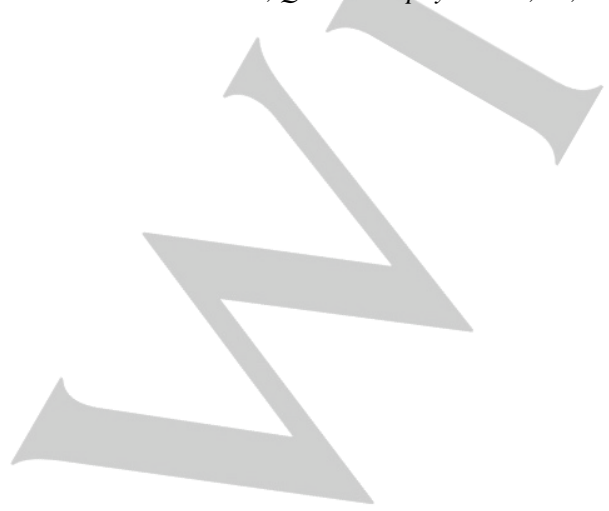




\section{Entry for the Table of Contents}

\section{COMMUNICATION}

Single-molecule imaging of the triple-helix formation in a DNA frame was demonstrated. The binding of the third strand to the doublestranded DNA was examined using two different types of triplet base pairs. The triple-helix formation was also examined using photocaged third strands. Third strand binding was observed directly by using highspeed atomic force microscopy with photoirradiation.

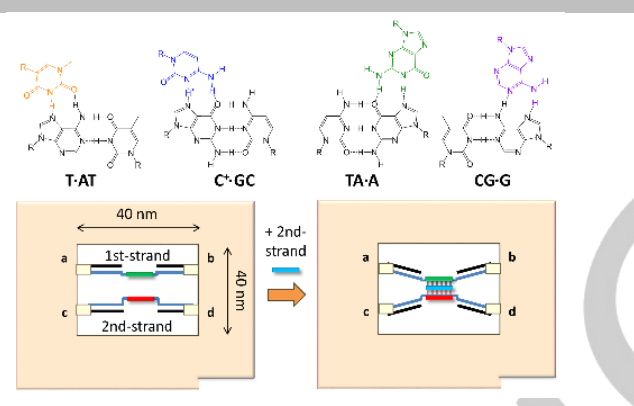

Yutaro Yamagata, ${ }^{[b]}$ Tomoko Emura, ${ }^{[b]}$ Kumi Hidaka, ${ }^{[b]}$ Hiroshi Sugiyama, ${ }^{*[a]}$ ${ }^{[b]}$ Masayuki Endo*[a]

Page No. - Page No.

Triple Helix Formation in a Topologically Controlled DNA Nanosystem 